\title{
PENINGKATKAN KUALITAS PELAYANAN PEMBUATAN IZIN MENDIRIKAN BANGUNAN (IMB) RUMAH TINGGAL MELALUI PROFESIONALISME KERJA DI BADAN PELAYANAN PENANAMAN MODAL DAN PERIJINAN TERPADU (BPPMPT) KOTA TANGERANG
}

\author{
Effendi ${ }^{\prime}$, Cecep Sudrajat ${ }^{2}$ \\ Universitas Muhammadiyah Tangerang, ${ }^{2}$ STISIP Yuppentek Tangerang \\ EffendiakI I@gmail.com
}

Keyword
Work Professionalism, Service
Quality, Building Permit

Abstract

This study aims to the extent to which the work professionalism of employees can improve the quality of service in building a Building Permit (IMB) at the Tangerang City One Stop Investment Service. The hypothesis proposed is: "There is a Positive Role of Employee Work Professionalism in Improving the Quality of Service for Building Construction Permits (IMB) in Tangerang City BPMPTSP".Based on the results of the study, it is known that there is a positive and significant role of work professionalism in improving the quality of residential IMB services.The higher the value of work professionalism, the higher the quality of service for the IMB of the Residence in Tangerang City BPMPTSP.The results of this study inform that the variable professionalism of work is an important factor in improving the quality of service for making residential building permits (IMB).

(C)2017 JMB, All right reserved

\section{PENDAHULUAN}

\section{Latar Belakang Masalah}

Sesuai Peraturan Daerah Kota Tangerang (perda) No 13 tahun 2014 tentang organisasi perangkat daerah, badan yang dipimpinnya berubah nomenklatur, dari sebelumnya Badan Pelayanan Penanaman Modal dan Perijinan Terpadu (BPPMPT), menjadi Badan Penanaman Modal dan Pelayanan Terpadu Satu Pintu (BPMPTSP) mulai tahun 20I5. Untuk tahun ini (2015) BPMPTSP Kota Tangerang menargetkan pemasukan dari sektor perizinan sebanyak Rp 60,2 miliar, dengan rincian target Izin Mendirikn Bangunan (IMB) Rp 54 miliar, Izin Gangguan (HO) Rp 3,5 miliar, Izin Trayek Rp 249 juta, dan Izin Mempekerjakan Tenaga Asing (IMTA) Rp.2,5 miliar.

Target Izin Mendirikn Bangunan (IMB) Rp 54 miliar yang begitu besar haruslah diimbangi dengan profesionalisme kerja pegawai agar dapat tercapai dalam pelayanan IMB. Sebagai lembaga pemerintah BPMPTSP Kota Tangerang, sedikitnya terdapat 60 jenis perizinan yang ada di Kota Tangerang, salah satunya adalah Pembuatan Izin Mendirikan Bangunan (IMB). Namun saat ini pelayanan pembuatan Izin Mendirikan Bangunan (IMB) tersebut dirasakan masih kurang dari berbagai aspek. Oleh sebab itu perlu ada suatu upaya untuk meningkatkan pelayanan tersebut.

Izin Mendirikan Bangunan (IMB) Rumah Tinggal merupakan izin yang diberikan untuk melakukan kegiatan membangun, masyarakat yang akan membangun sebaiknya mengurus IMB supaya bangunannya tidak dibongkar lagi ketika ada sidak dari instansi terkait. Dengan kata lain, masyarakat mestinya menyiapkan IMB agar proyek tetap berjalan atau tidak tertunda karena kasus perizinan ini.

Dalam pengurusan IMB sebaiknya diajukan sebelum pelaksanaan pengerjaan bangunan, sehingga pada saat pelaksanaan tidak terganjal dengan peraturan-peraturan yang berlaku. Pada umumnya waktu pemrosesan IMB lamanya 15 hari jam kerja terhitung dari waktu pengajuan yang pertama kali. Jangka waktu ini 
berbeda- beda tergantung kebijakan daerah pengawasan setempat dan kesiapan berkasberkas yang diperlukan. Waktu penyelesaian permohonan untuk rumah tinggal paling lambat 15-20 hari kerja sejak diterimanya permohonan yang telah memenuhi persyaratan dan telah membayar retribusi.

Pelayanan Izin Mendirikan Bangunan (IMB) Rumah Tinggal yang diberikan oleh Badan Penanaman Modal dan Pelayanan Terpadu Satu Pintu (BPMPTSP) dirasakan masih kurang dikarenakan adanya sebagian masyarakat yang mengeluhkan mengenai kualitas pelayanan Izin Mendirikan Bangunan (IMB) Rumah Tinggal tersebut, khususnya dari waktu pelayanan dan hal ini tentu saja menimbulkan perasaan tidak puas bagi masyarakat sebagai subyek yang memerlukan pelayanan Izin Mendirikan Bangunan (IMB) Rumah Tinggal tersebut, ditambah waktu penyelesaian IMB Rumah Tinggal terlalu lama dari yang di targetkan selama 15 hari jam kerja, namun waktu tersebut tidak berlaku jika hasil penelitian teknis dari permohonan masih memerlukan perbaikanperbaikan dan penyempurnaan, setelah adanya pemberitahuan secara tertulis dari dinas terkait nyatanya meskipun persyaratan lengkap akan tetapi pembuatan IMB Rumah Tinggal lebih dari I bulan lamanya bahkan lebih. Proses yang ditempuh sampai dengan 6 meja ini pun turut dirasakan tidak efektif dan lama, dan terkadang tertunda di meja bagian pemeriksaan berkas dan di meja tim teknis pada saat pemrosesan IMB Rumah Tinggal, sehingga masyarakat menunggu lama, sedangkan pengguna (masyarakat) sangat membutuhkan secepatnya untuk target pembangunan.

\section{Rumusan Masalah}

Berdasarkan latar belakang masalah, identifikasi masalah, dan pembatasan masalah maka konsentrasi masalah pada penelitian ini dapat dirumuskan sebagai berikut: bagaimanakah profesionalisme kerja pegawai dalam meningkatkan kualitas pelayanan pembuatan Izin Mendirikan Bangunan (IMB) Rumah Tinggal di BPMPTSP Kota Tangerang?

\section{TINJAUAN PUSTAKA}

\section{Profesionalisme}

Menurut Korten \& Alfonso (dalam Tjokrowinoto 1996:191) dijelaskan bahwa yang dimaksud dengan profesionalisme adalah kecocokan (fitness) antara kemampuan yang dimiliki oleh birokrasi (bureaucratic- competence) dengan kebutuhan tugas (taskrequirement). Terpenuhinya kecocokan antara kemampuan dengan kebutuhan tugas merupakan syarat terbentuknya pegawai yang profesional. Artinya keahlian dan kemampuan pegawai merefleksikan arah dan tujuan yang ingin dicapai oleh suatu organisasi.

Pendapat tersebut diperkuat juga oleh Atmosoeprapto (2000:5I) yang menyebutkan bahwa profesionalisme merupakan cermin dari kemampuan (competensi), yaitu memiliki pengetahuan (knowledge), keterampilam (skill), bisa melakukan (ability) ditunjang dengan pengalaman (experience) yang tidak mungkin muncul tiba-tiba tanpa melalui perjalanan waktu. Sedangkan arti kata profesionalisme menurut Siagian, (2000:163) adalah keandalan dalam pelaksanakan tugas sehingga terlaksana dengan mutu yang baik, waktu yang tepat, cermat dan dengan prosedur yang mudah dipahami dan diikuti oleh "klientele" (pelanggan atau masyarakat).

menurut Mertin Jr (dalam Islamy, 1998:25-26), karakteristik/ ciri-ciri sosok profesionalisme pegawai sesuai dengan tuntutan good governance, diantaranya, meliputi :

I. Equality: Perlakuan yang sama atas pelayanan yang diberikan. Hal ini didasarkan atas tipe perilaku birokrasi rasional yang secara konsisten memberikan pelayanan yang berkualitas kepada semua pihak tanpa memandang afilisasi politik, status sosial dan sebagainya. Bagi mereka memberikan perlakuan yang sama identik dengan berlaku jujur.

2. Equity : Perlakuan yang sama kepada masyarakat tidak cukup. Selain itu juga perlakuan yang adil. Untuk masyarakat yang pluralistik kadang-kadang diperlukan perlakuan yang adil dan perlakuan yang sama. (misalnya menghapus diskriminasi pekerjaan, sekolah, perumahan dan sebagainya) dan kadang-kadang pula diperlukan perlakuan yang adil tetapi tidak sama kepada orang tertentu (pemberian kredit tanpa bunga kepada pengusaha lemah dsb).

3. Loyalty : Kesetiaan diberikan kepada konstitusi, hukum, pimpinan, bawahan dan rekan kerja. Berbagai jenis kesetiaan tersebut terkait satu sama lain dan tidak ada kesetiaan yang mutlak diberikan kepada satu jenis kesetiaan tertentu dengan mengabaikan yang lainnya. 
4. Accountability : Setiap pegawai pemerintah harus siap menerima tanggung jawab atas apaun yang ia kerjakan dan harus menghindarkan diri dari sindroma "saya sekedar melaksanakan perintah atasan".

Menurut Siagian (2000) profesionalisme diukur dari segi kecepatannya dalam menjalankan fungsi dan mengacu kepada prosedur yang telah disederhanakan. Menurut pendapat tersebut, konsep profesionalisme dalam diri pegawai dilihat dari segi:

a. Kreatifitas (creativity).

Kemampuan pegawai untuk menghadapi hambatan dalam memberikan pelayanan kepada publik dengan melakukan inovasi. Hal ini perlu diambil untuk mengakhiri penilaian miring masyarakat kepada birokrasi publik yang dianggap kaku dalam bekerja. Terbentuknya pegawai yang kreatif hanya dapat terjadi apabila: terdapat iklim yang kondusif yang mampu mendorong pegawai pemerintah untuk mencari ide baru dan konsep baru serta menerapkannya secara inovatif: adanya kesediaan pemimpin untuk memberdayakan bawahan antara lain melalui partisipasi dalam pengambilan keputusan yang menyangkut pekerjaan, mutu hasil pekerjaan, karier dan penyelesaian permasalahan tugas.

b. Inovasi (innovasi),

Perwujudannya berupa hasrat dan tekad untuk mencari, menemukan dan menggunakan cara baru, metode kerja baru, dalam pelaksanaan tugasnya. Hambatan yang paling mendasar dari perilaku inovatif adalah rasa cepat puas terhadap hasil pekerjaan yang telah dicapai.

c. Responsifitas (responsivity).

Kemampuan pegawai dalam mengantisipasi dan menghadapi aspirasi baru, perkembangan baru, tuntutan baru, dan pengetahuan baru, birokrasi harus merespon secara cepat agar tidak tertinggal dalam menjalankan tugas dan fungsinya.

\section{Kualitas Pelayanan}

Pemerintahan pada hakekatnya adalah pelayanan kepada masyarakat. la tidaklah diadakan untuk melayani dirinya sendiri, tetapi untuk melayani masyarakat serta menciptakan kondisi yang memungkinkan setiap anggota masyaraakat mengembangkan kemampuan dan kreativitasnya demi mencapai tujuan bersama (Rasyid, 1998).

Konsep pelayanan umum menurut Finer (dalam Ndraha, 2003: 55) meliputi jasa publik dan jasa sipil. Pelayanan diperlukan guna memenuhi kebutuhan manusia, kebutuhan manusia ada yang bisa dipenuhi melalui pasar (private choice) ada yang hanya dipenuhi melalui proses secara istimewa. Kegiatan pelayanan tersebut dalam prosesnya menunjukkan hubungan atau interaksi antara pemberi layanan (pemerintahan atau birokrasi) dan penerima layanan (rakyat atau masyarakat).

Menurut Sinambela (2010: 6), secara teoritis tujuan pelayanan publik pada dasarnya adalah memuaskan masyarakat. Untuk mencapai kepuasan itu dituntut kualitas pelayanan prima yang tercermin dari :

I. Transparan

Pelayanan yang bersifat terbuka, mudah dan dapat diakses oleh semua pihak yang membutuhkan dan disediakan secara memadai serta mudah dimengerti.

2. Akuntabilitas

Pelayanan yang dapat dipertanggungjawabkan sesuai dengan ketentuan peraturan perundang-undangan.

3. Kondisional

Pelayanan yang sesuai dengan kondisi dan kemampuan pemberi dan penerima pelayanan dengan tetap berpegang pada prinsip efisiensi dan efektivitas.

4. Partisipatif

Pelayanan yang dapat mendorong peran serta masyarakat dalam

penyelenggaraan pelayanan publik dengan memperhatikan aspirasi, kebutuhan dan harapan masyarakat.

5. Kesamaan Hak

Pelayanan yang tidak melakukan diskriminasi dilihat dari aspek apapun khususnya suku, ras, agama, golongan, status sosial dan lainlain.

6. Keseimbangan Hak dan Kewajiban

Pelayanan yang mempertimbangkan aspek keadilan antara pemberi dan penerima pelayanan publik.

Menurut Dwiyanto (2008 : 343-344) ada beberapa dimensi dari kualitas pelayanan, yaitu:

I. Sikap Petugas;

2. Prosedur;

3. Waktu;

4. Fasilitas; dan 


\section{Pelayanan.}

Pada dimensi di atas diharapkan kualitas pelayanan dapat memenuhi harapan pengguna jasa dan dapat tercipta pelayanan yang efektif di dalam organisasi publik.

\section{Hipotesis}

Adapun kaitanya dengan kualitas pelayanan, profesionalsme adalah faktor pendukung yang tidak boleh ditinggalkan. Sarana dan prasarana yang memadai, lengkap dan canggih untuk mempercepat proses pelayanan yang diberikan kepada masyarakat tidak akan terlaksana, apabila pegawai yang melaksanakannya tidak profesional dalam arti tidak memiliki pengetahuan, tidak dapat memahami dan tidak mampu menggunkan serta mengendalikan prasarana tersebut, dan berkibat ketidakteraturan prosedur dalam pemberian pelayanan kepada masyarakat.

Dengan demikian profesionalseme kerja pegawai yang handal menghantarkan kepada pelayanan pembuatan ijin mendirikan bangunan (IMB) yang berkualitas, yaitu sikap petugas yang tanggap, kesesuaian prosedur pelayanan, ketepatan dan kecepatan proses pelayanan, mampu menguasai dan mengendalikan fasilitas- fasilitas penunjang pelayanan, mampu memberikan pelayanan prima.

Berdasarkan uraian tersebut di atas, maka peneliti membuat hipotesis penelitiannya yaitu: "Terdapat Peran Positif Profesionalisme Kerja Pegawai dalam Meningkatkan Kualitas Pelayanan Pembuatan Izin Mendirikan Bangunan (IMB) Rumah Tinggal di BPMPTSP Kota Tangerang".

\section{METODE PENELITIAN}

Penelitian ini menggunakan moetode kuantitatif. Melalui hasil penelitian ini diharapkan data atau informasi yang diperoleh dengan menggunakan instrumen daftar pernyataan atau kuesioner yang terpola dan terstruktur agar sesuai dengan judul penelitian serta data yang dibutuhkan.

\section{Operasional Variabel}

Dalam mengoperasionalkan variabelvariabel dalam penelitian ini, maka untuk langkah selanjutnya yaitu untuk mempermudah pembuatan kuesioner, peneliti memerlukan indikator-indikator yang sekiranya diperlukan, seperti tabel berikut ini :

Tabel I. Opersaionalisasi Variabel Penelitian

\begin{tabular}{|c|c|c|c|c|}
\hline NO & VARIABEL & INDIKATOR & BUTIR & JML \\
\hline \multirow{5}{*}{ I } & \multirow{5}{*}{$\begin{array}{l}\text { Profesionalisme Kerja (X) } \\
\text { Sumber: Atmosoeprapto, } \\
2000\end{array}$} & Kemampuan & 1 & 1 \\
\hline & & Pengetahuan & 2,3 & 2 \\
\hline & & Keterampilan & 4 & $\mathrm{I}$ \\
\hline & & Mampu melakukan & 5 & I \\
\hline & & Pengalaman & 6 & 1 \\
\hline \multirow{5}{*}{2} & \multirow{5}{*}{$\begin{array}{c}\text { Kualitas Pelayanan } \\
\text { (Y) } \\
\text { Sumber: Dwiyanto, } 2008\end{array}$} & Sikap & I & 1 \\
\hline & & Prosedur & 2,3 & 2 \\
\hline & & Waktu & 4 & I \\
\hline & & Fasilitas & 5 & $\mathrm{I}$ \\
\hline & & Pelayanan & 6 & $\mathrm{~T}$ \\
\hline \multicolumn{3}{|c|}{ Jumlah } & 12 & 12 \\
\hline
\end{tabular}

\section{Populasi dan Sampel}

Populasi obyek penelitian adalah jumlah di BPMPTSP Kota Tangerang yang berjumlah 76 orang, dengan demikian populasi pada penelitian ini berukuran 76 orang.

Pada penelitian ini ukuran sampel digunakan rumus dari Slovin (Umar Husein,

2003 : 78), yaitu : $n=\frac{N}{1+N e^{2}}$, dimana $\mathrm{n}$ adalah sampel, $\mathrm{N}$ adalah ukuran populasi, dan e adalah persen kelonggaran ketidaktelitian karena kesalahan pengambilan sampel yang masih dapat ditolerir. Untuk nilai e ini, peneliti menggunakan nilai sebesar $10 \%$.

$$
n-\frac{N}{11 \mathrm{Ne}^{2}} \frac{76}{1+76(0,01)}=\frac{76}{1.76}=43.18182 \approx 43
$$

Berdasarkan hasil perhitungan sampel tesebut, maka jumlah sampel untuk dijadikan responden 
berjumlah 43 orang pegawai yang melaksanakan pelayanan di BPMPTSP Kota Tangerang.

\section{Teknik dan Alat Pengumpulan Data}

Teknik pengumpulan data yang digunakan dalam penelitian ini terdiri dari :

a. Teknik survei dengan melalui penyebaran kuesioner.

b. Teknik studi kepustakaan

Untuk mengumpulkan data yang didapat dari berbagai sumber informasi, maka perlu menggunakan beberapa macam teknik pengumpulan data, yaitu :

a. Studi kepusatakaan, yaitu sumber informasi yang didapat dari buku-buku atau dokumendokumen lain yang berkaitan dengan masalah yang sedang diteliti.

b. Daftar pernyataan (kuesioner), yaitu sejumlah pertanyaan yang telah disediakan jawabannya secara pilihan ganda yang akan diberikan kepada responden sekitar permasalahan yang sedang diteliti dan sekiranya belum terlingkup dari data pustaka maupun kuesioner kepada sebagian pegawai yang ada.

Jawaban setiap item instrument padakuesioner yang menggunakan skala likert mempunyai gradiasi dari sangat positif sampai sangat negatif, dan dalam penelitian ini peneliti menggunakan kata-kata antara lain:

Sangat setuju dengan skor 5

Setuju dengan skor 4

Cukup setuju dengan skor 3

Kurang setuju dengan skor 2

Tidak setuju dengan skor I

\section{Teknik Analisis Data}

Teknik analisis statistik inferensial digunakan untuk menguji hipotesis yang diajukan dalam penelitian, alat analisis statistik inferensial terdiri dari :

I. Koefisien Korelasi Sederhana ( $r$ )

Alat analisis koefesien korelasi sederhana digunakan untuk menilai hubungan atau tingkat keeratan antara variabel dependen (Y) dengan masing-masing variabel independen (X). koefisien korelasi sederhana ini berdasarkan formula dari Pearson yang dirumuskan sebagai berikut :

\section{Ryx $\quad \mathrm{n} \Sigma \mathrm{XY}-(\Sigma \mathrm{X})(\Sigma \mathrm{Y})$ $\sqrt{ }\left\{\mathrm{n}\left(\Sigma \mathrm{X}^{2}\right)-(\Sigma \mathrm{X})^{2}\right\}\left\{\mathrm{n}\left(\Sigma \mathrm{Y}^{2}\right)-(\Sigma \mathrm{Y})^{2}\right\}$}

Dimana :

\begin{tabular}{|c|c|c|}
\hline Rxy & $\begin{array}{l}\text { Koefisien } \\
\text { antara } \\
\text { Profesionalis }\end{array}$ & korelas \\
\hline & $\begin{array}{l}\text { dan } \\
\text { pelayanan. }\end{array}$ & Kualitas \\
\hline$x$ & : Profesionalism & e kerja \\
\hline & : Kualitas pelay & nan \\
\hline
\end{tabular}

2. Koefisien Determinasi Sederhana $\left(\mathbf{r}^{2}\right)$

Alat analisis koefisien determinasi sederhana digunakan untuk mengetahui persentase besarnya perubahan variabel terikat $(\mathrm{Y})$, yang disebabkan oleh variabel bebas $(\mathrm{X})$. Koefisien determinasi ini berdasarkan formula dari Supranto (1990 :80) yang dirumuskan sebagai berikut :

$$
K D=r^{2} \times 100 \%
$$

Dimana :

KD: Koefisien determinasi sederhana

$r$ : Koefisien korelasi

\section{Regresi Sederhana}

Alat analisis regresi sederhana digunakan untuk memprediksi variabel terikat (Y) dengan melihat sifat hubungannya dengan variabel bebas $(\mathrm{X})$. Sifat hubungan antar variabel penelitian dapat dilihat dari tanda (+/-) Koefisien regresi sederhana dan besar kecilnya nilai koefisien regresi sederhana yang diperoleh dari hasil analisis data penelitian. Alat analisis regresi sederhana yang digunakan dalam penelitian ini menggunakan formula dari Putrawan (1990: II0), yaitu :

$$
\hat{\mathbf{Y}}=\mathbf{a}+\mathbf{b} \mathbf{X}
$$

Dimana :

$$
\begin{aligned}
& \hat{\mathrm{Y}} \text { : Prediksi Kualitas pelayanan } \\
& \text { a : Konstanta } \\
& \text { b : Koefisien regresi dari variabel } \\
& \text { bebasnya } \\
& X \text { : Faktor variabel bebas (Profesionalisme }
\end{aligned}
$$

\section{Rancangan Uji Hipotesis}

Rancangan uji hipotesis digunakan untuk menguji hipotesis yang diajukan pada penelitian, apakah nilai-nilai statistik yang dihasilkan dari hasil analisis statistik dapat digeneralisasikan terhadap populasi. Taraf signifikasi yang digunakan adalah sebesar $5 \%$.

Kriteria pengujian hipotesis adalah :

Jika nilai $\mathrm{t}$ test $\geq \mathrm{t}$ tabel, maka $\mathrm{H} 0$ ditolak

Jika nilai $\mathrm{t}$ test $<\mathrm{t}$ tabel, maka $\mathrm{H} 0$ diterima 


\section{HASIL PENELITIAN DAN PEMBAHASAN}

Hasil penelitian yang akan diuraikan oleh peneliti dibagi ke dalam tiga bagian pembahasan, yaitu I) deskripsi hasil penelitian, 2) analisis hasil penelitian meliputi: a. Pengujian persyaratan analisis, dan b Pengujian hipotesis. Dan 3) interpretasi hasil penelitian.

\section{Deskripsi Hasil Penelitian}

I. Profesionalisme Kerja

Gambaran tentang sebaran nilai pusat dari data Profesionalisme Kerja di BPMPTSP Kota Tangerang dapat dilihat pada tabel berikut ini :

Tabel 2. Distribusi Skor Profesionalisme

\section{Kerja}

Statistics

Profesionalisme Kerja

\begin{tabular}{|c|c|c|}
\hline & \multicolumn{2}{|c|}{ Valid } \\
\hline & Mean Missing & $\begin{array}{r}0 \\
16,65\end{array}$ \\
\hline \multicolumn{2}{|c|}{ Std. Deviation } & 3,221 \\
\hline \multicolumn{2}{|c|}{ Range } & 12 \\
\hline \multicolumn{2}{|c|}{ Minimum } & 10 \\
\hline \multicolumn{2}{|c|}{ Maximum } & 22 \\
\hline
\end{tabular}

Sumber : Hasil Analisis Data Kuantitatif Kuesioner, Penelitian 2016

Untuk lebih memperjelas distribusi data, berikut ini akan disajikan diagram batang yang dipresentasikan pada Diagram Batang pada Gambar berikut ini:

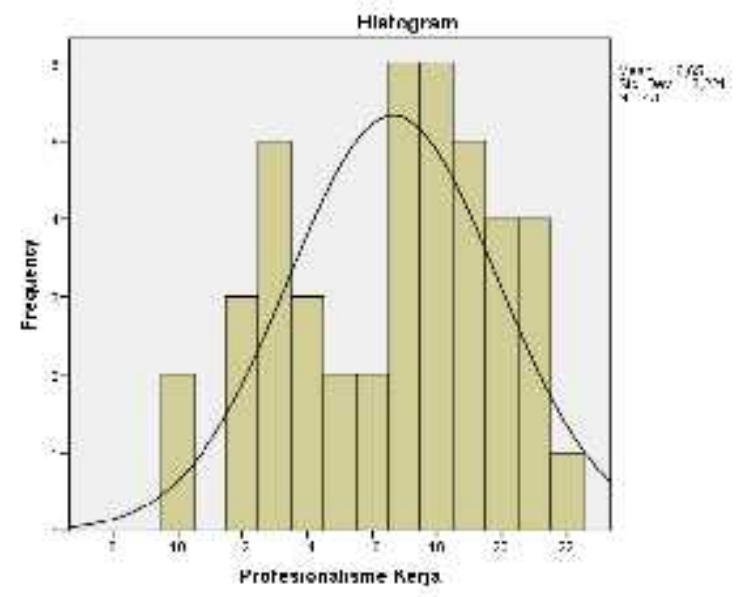

\section{Gambar I. Diagram Batang Variabel} Profesionalisme Kerja
Pada Gambar I memperkuat pernyataan distribusi data akan menyebar normal, bila ada penumpukan angka di bagian tengah, sedang kecenderungan angka akan menurun di awal dan pada akhirnya setelah melewati titik maksimal akan terjadi penurunan angka kembali.

\section{Kualitas Pelayanan}

Gambaran tentang sebaran nilai pusat dari data Kualitas Pelayanan di BPMPTSP Kota Tangerang dapat dilihat pada tabel berikut ini :

Tabel 3. Distribusi Skor Variabel Kualitas Pelayanan

Statistics

Profesionalisme Kerja

\begin{tabular}{|l|r|}
\hline$N$ & Valid \\
Mean & Missing \\
Std. Deviation & 0 \\
Range & 16,72 \\
Minimum & 3,050 \\
Maximum & 12 \\
\hline
\end{tabular}

Sumber : Hasil Analisis Data Kuantitatif Kuesioner, Penelitian 2016

Selanjutnya dapat dilihat pada diagram batang bagaimna sebaran data untuk variabel Kualitas Pelayanan

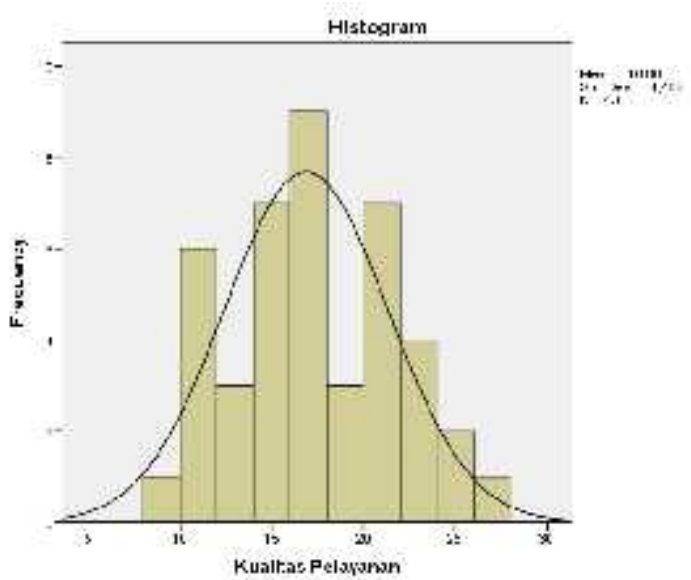

\section{Gambar 2. Diagram Batang Variabel Kualitas Pelayanan}

Pada Gambar 2 distribusi data menyebar normal, karena ada penumpukan angka di bagian tengah, sedang kecenderungan angka akan menurun di awal dan pada akhirnya setelah melewati titik maksimal akan terjadi penurunan angka kembali. 


\section{Uji Validitas}

Pengujian validitas data dari jawaban responden dimaksudkan untuk mengetahui, seberapa banyak butir soal dalam kuesioner yang dibagikan ini bersifat valid (sah).

Profesionalisme Kerja terdapat 6 butir soal yang dibagikan kepada 43 responden, sehingga korelasi yang dihasilkan sebanyak 6 korelasi, dan nilai korelasi untuk masing-masing butir soal dapat dilihat dalam tabel berikut :

Tabel 4. Hasil Analisis Uji Validitas Data Profesionalisme Kerja

\begin{tabular}{|c|c|c|}
\hline No.Item & $\begin{array}{c}\text { Koefisien } \\
\text { Korelasi }\end{array}$ & Keterangan \\
\hline \hline I. & 0,40 & Valid \\
2. & 0,65 & Valid \\
3. & 0,36 & Valid \\
4. & 0,42 & Valid \\
5. & 0,64 & Valid \\
6. & 0,57 & Valid \\
\hline
\end{tabular}

Sumber : Hasil Analisis Data Kuantitatif Kuesioner, Penelitian 2016
Tabel 5. Hasil Analisis Uji Validitas Data Variabel Kualitas Pelayanan

\begin{tabular}{|c|c|c|}
\hline No.Item & $\begin{array}{c}\text { Koefisien } \\
\text { Korelasi }\end{array}$ & Keterangan \\
\hline \hline I. & 0,42 & Valid \\
2. & 0,40 & Valid \\
3. & 0,73 & Valid \\
4. & $0,6 \mathrm{I}$ & Valid \\
5. & $0,7 \mathrm{I}$ & Valid \\
6. & 0,65 & Valid \\
\hline
\end{tabular}

Sumber : Hasil Analisis Data Kuantitatif Kuesioner, Penelitian 2016

\section{Uji Relibilitas}

Pengujian reabilitas instrumen dilakukan dengan internal consistency dengan teknik belah dua (split half) yang dianalisis dengan rumus Spearman Brown. seperti berikut :

$$
r_{i}=\frac{2 r_{b}}{1+r_{b}}
$$

Hasil reliablitas untuk masing-masing variabel yang disajikan dalam tabel berikut :

Tabel 6. Hasil Pengujian Reliabilitas Data Variabel Penelitian

\begin{tabular}{|c|c|c|c|c|c|}
\hline No. & Variabel & Korelasi & Spearman Brown & Nilai Kritis & Kesimpulan \\
\hline \hline I. & $\mathrm{X}$ & 0,907 & 0,951 & 0,300 & Data Reliabel \\
\hline 2. & $\mathrm{Y}$ & 0,548 & 0,708 & 0,300 & Data Reliabel \\
\hline
\end{tabular}

Sumber : Hasil Analisis Data Kuantitatif Kuesioner, Penelitian 2016

Beradasarkan Tabel 6di atas dapat diketahui bahwa hasil korelasi skor butir ganjil dengan butir genap untuk Profesionalisme Kerja adalah sebesar 0,907 , sedangkan untuk variabel Kualitas Pelayanan Pembuatan Izin Mendirikan Bangunan (IMB) Rumah Tinggal adalah sebesar 0,548 . Atas hasil perhitungan tersebut diperoleh nilai korelasi Spearman-Brownnya variabel $X$ sebesar 0,95I untuk Profesionalisme Kerja dan 0,708 untuk variabel Kualitas Pelayanan Pembuatan Izin Mendirikan Bangunan (IMB) Rumah Tinggal. Dengan demikian, untuk kedua variabel penelitian keduanya dapat memenuhi syarat untuk dikatakan reliabel, karena hasil perhitungan korelasi sudah lebih besar daripada nilai kritisnya, yaitu 0,300.

\section{Uji Normalitas}

Untuk menguji normalitas data dari masing-masing variabel, peneliti menggunakan software SPSS, yang hasilnya adalah sebagai berikut:

Tabel 7. Hasil Pengujian Normalitas Data

One-Sample Kolmogorov-Smirnov Test

\begin{tabular}{|ll|r|}
\hline & & $\begin{array}{r}\text { Unstandardize } \\
\text { d Residual }\end{array}$ \\
\hline $\mathrm{N}$ & Mean & 43 \\
Normal Parametersa,b & Std. Deviation &, 0000000 \\
& Absolute &, 07628008 \\
Most Extreme & Positive &, 054 \\
Differences & Negative &, 054 \\
Kolmogorov-Smirnov Z & &,- 045 \\
Asymp. Sig. (2-tailed) & &, 354 \\
\hline
\end{tabular}

a. Test distribution is Normal.

b. Calculated from data.

Sumber : Hasil Analisis Data Kuantitatif Kuesioner, Penelitian 2016 
Berdasarkan Tabel 7 diketahui nilai signifikansi senilai I,000 lebih besar dari 0,05, sehingga dapat disimpulkan bahwa data yang diuji berdistribusi normal.

\section{Uji Linieritas}

Untuk menguji linearitas data diantara variabel bebas dengan variabel terikatnya, peneliti menggunakan alat analisis pengujian meanyang dibantu dengan software SPSS, yang hasilnya perhitungannya disajikan dalam tabel yang ada di halaman berikut ini.

\section{Tabel 8. Hasil Pengujian Linearitas}

ANOVA Table

\begin{tabular}{|c|c|c|c|c|c|c|c|}
\hline & & & $\begin{array}{l}\text { Sum of } \\
\text { Squares }\end{array}$ & $d f$ & $\begin{array}{l}\text { Mean } \\
\text { Square }\end{array}$ & $\mathrm{F}$ & Sig. \\
\hline \multirow{6}{*}{$\begin{array}{l}\text { Kualitas Pelayanan * } \\
\text { Profesionalisme Kerja }\end{array}$} & \multirow{4}{*}{$\begin{array}{l}\text { Between } \\
\text { Groups }\end{array}$} & (Combined) & 372,794 & 12 & 31,066 & 2,002 & ,061 \\
\hline & & Linearity & 207,346 & I & 207,346 & 13,359 & ,001 \\
\hline & & Deviation & 165,448 & II & $|5,04|$ & ,969 & ,494 \\
\hline & & $\begin{array}{l}\text { from } \\
\text { Linearity }\end{array}$ & & & & & \\
\hline & Within Groups & & 465,625 & 30 & $|5,52|$ & & \\
\hline & Total & & 838,419 & 42 & & & \\
\hline
\end{tabular}

Sumber : Hasil Analisis Data Kuantitatif Kuesioner, Penelitian 2016

Berdasarkan tabel di atas dapat diketahui nilai linearity $(F)$ untuk hubungan Profesionalisme Kerja dengan Kualitas Pelayanan adalah sebesar 13,359 dan dengan tingkat signifikasi sebesar 0,001 . Dengan hasil tersebut, maka dapat disimpulkan bahwa hubungan diantara data variabel bebas dengan data variabel terikat adalah berhubungan secara linear dan memenuhi syarat untuk pengujian regresi linear sebab hasil pengujian linear menunjukkan signifikasi pada $\alpha$ kurang dari $5 \%(0,000)$.

\section{Pengujian Hopitesis}

I) Uji Korelasi Sederhana

hasil analisis korelasi produk momen antara variabel bebas dengan variabel terikat dirangkum ke dalam tabel berikut :

Tabel 9. Hasil Uji Korelasi Produk Momen Correlations

\begin{tabular}{|c|c|c|c|}
\hline & & $\begin{array}{c}\text { Profesionalisme } \\
\text { Kerja }\end{array}$ & $\begin{array}{l}\text { Kualitas } \\
\text { Pelayanan }\end{array}$ \\
\hline \multirow{4}{*}{ Profesionalisme Kerja } & Pearson Correlation & 1 &, $497^{* *}$ \\
\hline & Sig. (2-tailed) & & ,001 \\
\hline & $\mathrm{N}$ & 43 & 43 \\
\hline & Pearson Correlation &, $497^{* *}$ & I \\
\hline \multirow[t]{2}{*}{ Kualitas Pelayanan } & Sig. (2-tailed) &, 001 & \\
\hline & $\mathrm{N}$ & 43 & 43 \\
\hline
\end{tabular}

**. Correlation is significant at the 0.0 l level (2-tailed).

Sumber : Hasil Analisis Data Kuantitatif Kuesioner, Penelitian 2016

Untuk mengukur tingkat keeratan korelasi antara variabel, Sugiyono (2007: 149) mempunyai kriteria untuk menginterpretasikan nilai koepfisien korelasi $(r)$ hasil di atas, yaitu :
$0,10-0,199=$ terdapat korelasi sangat rendah
$0,20-0,399=$ terdapat korelasi rendah
$0,40-0,599=$ terdapat korelasi sedang
$0,60-0,799=$ terdapat korelasi kuat
$0,80-1,000=$ terdapat korelasi kuat sekali

Dengan demikian korelasi antara Profesionalisme Kerja dengan Kualitas Pelayanan Pembuatan Izin Mendirikan Bangunan (IMB) Rumah Tinggal mempunyai nilai korelasi 0,497 dan termasuk kriteria korelasi "sedang" (0,40 $0,599)$.

2) Uji Koefisien Determinasi

Analisis koefisien determinasi antara variabel bebas dengan variabel terikat hasil analis melalui SPSS V.2I terlihat dalam tabel berikut : 
Tabel 10. Hasil Uji Koefisien Determinasi Model Summary

\begin{tabular}{|r|r|r|r|}
\hline$R$ & $R$ Square & $\begin{array}{c}\text { Adjusted R } \\
\text { Square }\end{array}$ & $\begin{array}{c}\text { Std. Error of } \\
\text { the Estimate }\end{array}$ \\
\hline, 497 &, 247 &, 229 & 3,923 \\
\hline
\end{tabular}

The independent variable is Profesionalisme Kerja.

Sumber : Hasil Analisis Data Kuantitatif Kuesioner, Penelitian 2016

\section{Profesionalisme Kerja meningkatkan} Kualitas Pelayanan Pembuatan Izin Mendirikan Bangunan (IMB) sebesar 24,70\%, sedangkan sisanya $75,30 \%$ adalah peran variabel lain yang dikelompokan pada epsilon (variabel bebas) yang tidak diteliti, namun mempengaruhi variabel terikat, dalam hal ini variabel Kualitas Pelayanan Pembuatan Izin Mendirikan Bangunan (IMB) Rumah Tinggal.

3) Uji Persamaan Garis Regresi

Hasil perhitungan yang didapat adalah seperti disajikan dalam tabel berikut.

\section{Tabel I I. Persamaan Garis Regresi Linear}

Coefficients $^{a}$

\begin{tabular}{|c|c|c|c|c|c|}
\hline \multirow[t]{2}{*}{ Model } & \multicolumn{2}{|c|}{ Unstandardized Coefficients } & \multirow{2}{*}{$\begin{array}{c}\begin{array}{c}\text { Standardized } \\
\text { Coefficients }\end{array} \\
\text { Beta }\end{array}$} & \multirow[t]{2}{*}{$\mathrm{t}$} & \multirow[t]{2}{*}{ Sig. } \\
\hline & $B$ & Std. Error & & & \\
\hline (Constant) & 4,702 & 3,373 & & 1,394 & , 171 \\
\hline Profesionalisme Kerja & ,729 &, 198 & ,497 & 3,670 &, 001 \\
\hline
\end{tabular}

a. Dependent Variable: Kualitas Pelayanan

Sumber : Hasil Analisis Data Kuantitatif Kuesioner, Penelitian 2016

Dengan demikian persamaan garis linear yang diketahui adalah mempunyai persamaan $\hat{Y}=4,702+0,729 X$. Untuk memperjelas kecenderungan perubahan nilai variabel terikat yang disebabkan berubahnya variabel bebas pada analisis regresi linear, diilustrasikan melalui gambar berikut ini:

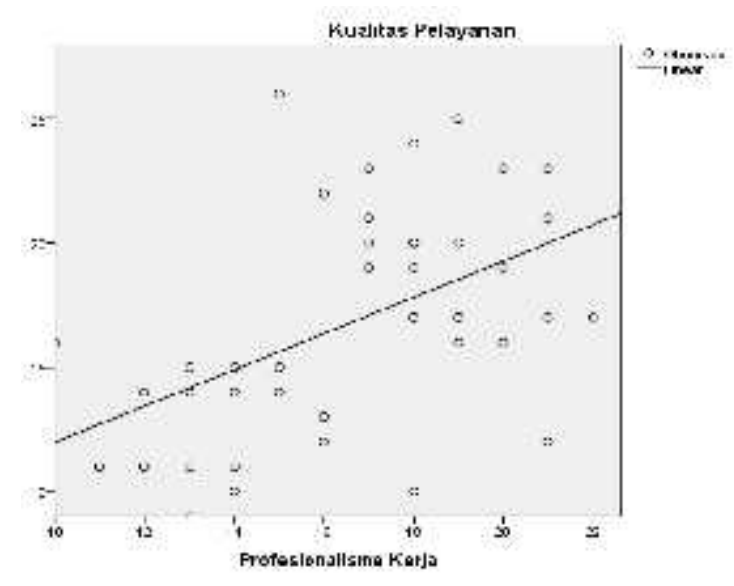

\section{Gambar 3. Prediksi Variabel Kualitas Pelayanan}

\section{Uji Statistik (Uji t)}

padaTabel II nilai t hitung sebesar 3,670

bernilai positif dan nilai $t$ tabel sebesar 2,0I3.

Disimpulkan $\mathrm{t}$ hitung $>\mathrm{t}$ tabel, yang berarti $\mathrm{Ha}$ di terima dan Ho ditolak. Hipotesis yang menyatakan : Terdapat Peran Positif Profesionalisme Kerja Pegawai dalam
Meningkatkan Kualitas Pelayanan Pembuatan Izin Mendirikan Bangunan (IMB) Rumah Tinggal di BPMPTSP Kota Tangerang", terbukti mempunyai peran atau pengaruh positif dan signifikan pada selang kepercayaan $95 \%$.

\section{Pembahasan}

Hasil perhitungan korelasi produk momen menghasilkan nilai korelasi sebesar 0, 497. Sehingga dapat disimpulkan bahwa terdapat peran sedang atau moderatProfesionalisme Kerja terhadap Kualitas Pelayanan di BPMPTSP Kota Tangerang.

Dengan menggunakan metode uji determinasi. Hasil pengujian determinasi adalah sebesar 24,70\%. Dengan demikian dapat disimpulkan bahwa Profesionalisme Kerja berperan dalam meningkatkan Kualitas adalah sebesar 24,70\%. Namun dengan hasil perhitungan koefisien determinasi, menunjukkan bahwa masih ada variabel lain yang mampu mempengaruhi atau memiliki peran dalam meningkatkan Kualitas Pelayanan di BPMPTSP Kota Tangerang, yaitu sebesar $75,30 \%$. Akan tetapi keberadaan variabel ini hanya sebatas untuk diketahui.

Berdasarkan hasil perhitungan analisis regresi linear diperoleh sebuah persamaan garis regresi linear yang memenuhi persamaan $\hat{Y}=4,702+0,729 X$. Model persamaan garis regresi linear ini, menurut peneliti dapat membantu Kepala Badan selaku pimpinan 
organisasi dan pimpinan bidang dalam membuat konsep untuk meningkatkan Kualitas Pelayanan Pembuatan Izin Mendirikan Bangunan (IMB) Rumah Tinggal kepada masyarakatKota Tangerang.

Dengan mengubah-ubah nilai Profesionalisme Kerja maka besaran target Kualitas Pelayanan Pembuatan Izin Mendirikan Bangunan (IMB) Rumah Tinggal dapat diprediksikan. Sehingga apabila ingin meningkatkan Kualitas Pelayanan Pembuatan Izin Mendirikan Bangunan (IMB) Rumah Tinggal, maka dengan meningkatkan (mengubah) Profesionalisme Kerja, melalui indikator Kemampuan (competensi), Pengetahuan (knowledge), Keterampilam (skill), Mampu melakukan (ability), dan Pengalaman (experience).

\section{Kesimpulan}

\section{PENUTUP}

Berdarakan hasil penelitian, diketahui terdapat peran positif dan signifikan profesionalisme kerja dalam meningkatkan kualitas pelayanan IMB Rumah Tinggal.

Semakin tinggi nilai profesionalisme kerja, maka semakin tinggi kualitas pelayanan IMB Rumah Tinggal di BPMPTSP Kota Tangerang.

\section{Saran}

I. Peningkatan kemampuan pegawai dengan memberikan pendidikan dan pelatihan seperti:
a. Pelatihan untuk menggambar Bestek Rumah;
b. Pelatihan mengitung retribusi;
c. Membuat dan menetahui site plant ataupetarencanapeletakan bangunan;
d. Mengetahui pengukuran Koefisien Dasar Bangunan (KDB), dan Koefisien Luas Bangunan (KLB).

2. Memberikan pengetahuan kepada pegawai tentang persyaratan dan ketentuan dalam Izin Mendirikan Bangunan beserta regulasinya, pengetahuan tentang prosedur pelayanan, pengetahuan tentang perizinan IMB yang terkait dengan pekerjaannya;

3. Meningkatkan keterampilan kerja dengan mengikuti pelatihan-pelatihan teknik dalam mengoperasikan sistem di konter pelayanan agar terlatih cepat dalam menangani dan memproses pelayanan, banyak belajar dan fokus pada tugas yang diberikan, dan adanya kesediaan atau komitmen untuk melakukan pekerjaan, serta belajar dari pengalaman untuk memperbaiki dan meningkatkan kerjanya dalam memberikan pelayanan di BPMPTSP Kota Tangerang.

\section{Daftar Pustaka}

Arikunto, Suharsimi, 1996. Prosedur Penelitian Suatu Pendekatan Praktek, Jakarta: PT. Rineka Cipta.

Atmosoeprapto, Kisdarto, 2000. Menuju SDM

Berdaya - Dengan Kepemimpinan Efektif

Dwiyanto, Agus 2006. Menwujudkan Good Governance melalui Pelayanan Publik. Gajah Mada University Press.

Handoko, H. 1999. Manajemen Personalia dan Sumberdaya Manusia. BPFE. Yogyakarta

Islamy, M. Irfan, 200I. Prinsip-Prinsip Perumusan Kebijaksanaan Negara. PT Bumi Aksara, Jakarta

Kountur, Ronny. 2005. Metode Penelitian Untuk Penulisan Skripsi dan Tesis, Jakarta: PPM.

Ndraha. Taliziduhu. 2003. Kybernology (IImu Pemerintahan Baru) Jilid I dan II. Jakarta, PT. Rineka Cipta.

Osborne, David dan Ted Gaebler. 1996. Mewirausahakan Birokrasi (Reiventing Govenrment); Mentransformasikan Semangat Wirausaha ke Dalam Sektor Publik. Edisi Keempat. Jakarta : Penerbit PPM.

Pamudji, S. 1993. Kepemimpinan Pemerintahan di Indonesia, Penerbit Jakarta : PT. Bina Aksara

Putrawan, I Made. 1990 Pengujian Hipotesis dalam Penelitian-Penelitian Sosial. Rineka Cipta, Jakarta.

Peraturan Daerah Kota Tangerang No. 13 Tahun 20I4 TentangOrganisasi Perangkat Daerah

Peraturan Walikota Tangerang Nomor 34 Tahun 2008 Tentang Organisasi dan Tata Kerja Dinas Pemadam Kebakaran

Siagian, P. Sondang. 2000. Fungsi-fungsi Manajerial. Jakarta: Bumi Aksara.

Sinambela, Lijan Poltak, 2010. Reformasi Pelayanan Publik: Teori, Kebijakan, dan Implementasi,Jakarta, Penerbit Bumi Aksara.

Sugiyono, 2002. Metode Penelitian Administrasi, Bandung: Alfabeta.

Tjiptono, F. \& Diana, A. 1995 Total Quality Management. Yogyakarta. Andi Ofset. 
Tjiptono. F., 2004, Prinsip-prinsip Total Quality Service, Penerbit Andi Yogyakarta.

Undang-undang Nomor 25 Tahun 2009 tentang Pelayanan Umum

Widodo, Erna dan Mukhtar. 2000. Konstruksi Ke Arah Penelitian Deskriptif, Yogyakarta : Avyrous.

Widodo, Joko, 200I, Good Governance, Telaah dari Dimensi Akuntabilitas dan kontrol Birokrasi Pada Ewra Desentralisasi dan Otonomi Daerah, Insan Cendikia, Surabaya. 